\title{
Identification and assessment of direct and indirect economic effects of the sports sector on the economy
}

\author{
Timur Kramin ${ }^{1, *}$, Marsel Miftakhov², and Dmitry Manushin ${ }^{1}$ \\ ${ }^{1}$ Kazan Innovative University named after V.G. Timiryasov (IEML), Kazan, Russia \\ ${ }^{2}$ State Council (Parliament) of the Republic of Tatarstan, Volga Region University of Sports and \\ Tourism, Kazan, Russia
}

\begin{abstract}
The sports sector makes a significant multilateral contribution to the development of economic systems. This study examines the scale and structure of the impact of the sports sector on the economy. Direct and indirect effects of such an impact are highlighted. The significance of the indirect socio-economic effects of major sporting events is illustrated by the example of the 2013 Universiade project in Kazan. On the basis of empirical data, the growth of sports activity of the population of the Republic of Tatarstan during the Universiade is shown. Using previously obtained econometric models on the indirect effects of the growth of the sports activity of the population, the indirect socio-economic effects of the Universiade were estimated: the infrastructural effect, a decrease in health care costs, an increase in labor productivity, additional income from tourism, and the creation of additional social capital. An extended model for assessing the payback of large sporting events, including investments in the infrastructure capital of the region and a number of intangible assets, is proposed and tested.
\end{abstract}

\section{Introduction}

The production and sale of sporting goods and the provision of sporting services generate significant direct economic benefits, comparable to a few percent of the gross domestic product in a number of developed countries. Spending on sports and outdoor activities should primarily be seen as direct benefits to the economic system, accounting for about $2 \%$ of household spending in the UK, New Zealand, Canada and Australia [1]. Imports and exports of sports services and goods also contribute significantly to GDP and are growing faster than economies in most countries, together with spending on sports. State statistics services in a number of countries take into account both direct and indirect effects of the sports sector. In addition, the experience of other countries shows that the sports field presents good business opportunities. At the same time, Russia still has to build a full-fledged system of accounting for the sports sector for the economy. To assess the actual level of household spending on

\footnotetext{
* Corresponding author: $\underline{\text { Kramin@ } @ \text { ieml.ru }}$
} 
sports, as well as the potential for exports and imports in Russia, a separate economic analysis of the available data is required. The purpose of this work is to generalize the existing experience in assessing the impact of sports on the economy and to substantiate, systematize and evaluate the direct and indirect effects of sports activity, using the example of the 2013 Universiade project in Kazan.

\section{Substantiation of the methodological basis of the research}

The study identifies and evaluates the direct and indirect effects of sports. Sport contributes directly to the economy by increasing employment. Sports employ about $2 \%$ of population in paid work in Australia, Canada, Great Britain and Scotland and 1.3\% in New Zealand [1]. The number of jobs created in the sports sector is at a comparable level or higher than in some traditional industries for statistical reporting. For example, the number of people employed in the sports and leisure industry in New Zealand is greater than in insurance, almost as much as in heavy industry. The sports sector is more employed in terms of the number of people than fishing, forestry, mining and oil industries combined.

Sports tourism, which is a separate market segment, should be named as a vivid indirect effect of sports [2-4]. In all countries covered in this study, sports and recreation are now an important and growing source of new jobs.

Community sports programs in most countries provide physical infrastructure, promote athletic activity and sport, stimulate physical education and sports activities, and support major sporting events. These activities are usually carried out by specialized sports organizations with funding from central government, local governments, sports lotteries, charitable organizations and commercial sponsorship.

As a result, governments receive significant direct tax revenue from the sports sector and indirect fiscal effects such as lower health care costs.

The total direct economic impact of sport ranges from $0.5 \%$ to $2 \%$ of GDP. In Canada, $1 \%$ of the contribution to GDP is similar to that of the timber, logging and paper industries and is half the size of the food industry [1]. In the UK, sports account for a quarter of the size of the healthcare industry. This shows that sport is a relatively large-scale business in these countries.

Improving health, lowering health care costs and increasing productivity at work are major benefits for people in sports, and they provide indirect benefits to individuals, the economy and society as a whole.

The following indirect economic effects are usually identified: sectoral links measured using multipliers; the business benefits of increased productivity through reduced absenteeism and increased productivity from those with athletic and healthy lifestyles. Reducing the incidence of sports-active people for a number of diseases also reduces health care costs. These effects have been shown to significantly outweigh the costs associated with sports injuries.

Studies based on the data of Russian regions, in which the impact of the sports activity of the population of the region on its social and economic development was assessed, confirmed the decrease in the total number of days of disability due to illness of the economically active population of different territories, on the example of the Republic of Tatarstan [5]. In addition, it is shown that an increase in the sports activity of the population contributes to a decrease in the number of offenses in the Republic of Tatarstan. These strictly mathematically substantiated results stimulated further research on the mechanisms of the influence of the population's sports activity on the socio-economic development of the regions of Russia.

The use of the European experience in studying and evaluating the sports sector of the economy is indicative. From this point of view, the use of the so-called Vilnius definition of 
the sports industry is important. In our study, we used an expanded definition of the sports industry - Version 2.0, "Definition of Vilnius", adopted in the CPA 2008, which distinguish between its statistical, narrow and broad definition as follows [6]:

1. Statistical definition: includes article 92.6 from the statistical classification of the European Union (NACE Rev. 1.1, NACE comes from the French "Nomenclature statistique des Activités économiques dans la Communauté Européenne" (Statistical classification of economic activities in the European Community), approved in July 2002), Statistical Classification of Economic Activities in the European Community, includes the sector of organized sports (sports clubs, public sports grounds, organizers of sports events). Only this definition of the sports industry (sector) corresponds to its own category in European statistics.

2. Narrow economic definition of the sports industry: includes the organized sports sector and, in addition, all activities that produce goods and services necessary for physical education and sports.

3. The broad economic definition of the sports industry includes all activities included in the narrow economic definition and, in addition, all other activities that are somehow related to sports activities, including those dependent on it.

Thus, the "Vilnius definition of the sports industry" is an overview of all product and service groups that are included in the so-called sports satellites account (see table 1).

Table 1. Examples of activities of satellites in the sports industry.

\begin{tabular}{|c|c|c|}
\hline \multicolumn{3}{|c|}{ Goods and services necessary for sports } \\
\hline School education & Sports equipment & Sportswear and shoes \\
\hline Dance schools & Sports vehicles & Clocks and timepieces \\
\hline Fitness centers & Equine & Sports weapons \\
\hline $\begin{array}{c}\text { Sports clubs, organizations, } \\
\text { unions, etc. }\end{array}$ & Stadiums and outdoor areas & Pools \\
\hline \multicolumn{3}{|c|}{ Sports-related goods and services } \\
\hline Medical Services & Tourism and Hospitality & $\begin{array}{c}\text { Television and } \\
\text { Telecommunications }\end{array}$ \\
\hline Veterinary & $\begin{array}{c}\text { Medicine Nutritional } \\
\text { Supplements } \\
\text { and sports nutrition }\end{array}$ & Bookmaker business \\
\hline
\end{tabular}

Thus, the definition we have considered is a definition of the sport itself as a classification of product groups and services. The results of the SportsEconAustria study show that the contribution of sports activities according to statistical, narrow and broad economic definitions to the total GDP of the European Union is $0.28 \%, 1.13 \%$ and $1.76 \%$, respectively [7].

Thus, depending on the used definition of a group of activities in the field of sports, the assessment of its contribution to GDP can be increased six times relative to the official statistics of the EU only when taking into account the direct effects. Accounting for the indirect effects of sports activity will give an additional increase in this indicator.

According to the statistical, narrow and broad definitions of sports activity in the sportsrelated sector, in 2005 gross value added was created in the amount of 28, 112 and 174 billion euros, respectively, taking into account only direct effects [7].

Figure 1 below shows the ten economic sectors of the European Union that contribute most to the creation of added value from sports activities, according to the broad definition of the sports industry. The Recreational and Sports Services and Educational Services sectors generate more value added, followed by hotel and restaurant services (see Figure 1). 


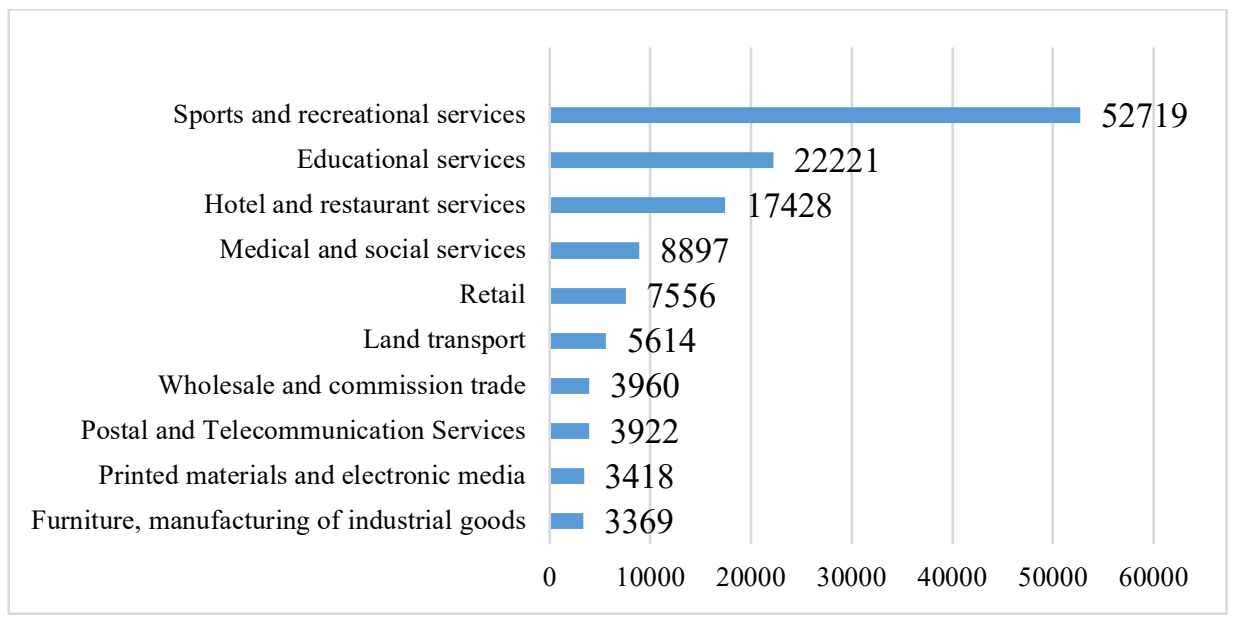

Fig. 1. Top ten sports-related sectors of the European Union economy with the greatest contribution to the creation of added value as a result of the implementation of sports activities, million Euro. Source: Report SportsEconAustria, 2012, [7].

Unfortunately, statistics for Russia, similar to those in Figure 1, are not generated. Nevertheless, the nature and structure of the impact of the sports industry in Russia is similar, which makes it possible to identify the main channels of the impact of sports activity on the socio-economic development of Russia.

\section{Results of the study: building an extended payback model of large-scale sports activities, on the example of the Republic of Tatarstan}

According to international statistics, not all major sporting events have a positive total economic effect. In other words, the costs of them do not always pay off. However, when calculating the payback of sports events, their direct effects are mainly calculated in the form of creating additional added value and increasing employment of the population. At the same time, many indirect effects are not taken into account. Taking into account the main indirect positive effects can change the final result of assessing the payback of such projects - their overall socio-economic effect will become positive, and the projects themselves, therefore, will become recouping.

The essence of the extended model for assessing the payback of major sporting events proposed in this section is to substantiate and take into account a number of indirect effects of major sporting events that were not previously included in similar calculations.

The models constructed within the framework of the study prove the existence of the influence of sports activity on the social and human capital of economic systems, using the example of the regions of Russia. These models can be taken as a basis for predicting the growth of these types of capital as a result of a given increase in sports activity.

In addition, in earlier studies [8-9], models for assessing the contribution of these types of capital to the economic growth of Russian regions have been constructed. Thus, additional indirect effects of sports activity on the economic development of Russian regions have been substantiated.

The decrease in the incidence of the population (expressed in the specific decrease in the days of incapacity for work) caused by the increase in its sports activity also has other significant economic effects. 
First, the labor productivity of the economically active population is increasing. This increase can be rigorously estimated (predicted) for a given increase in sports activity based on the constructed models. Secondly, the effect of reducing budget expenditures on health care is quite measurable. Both of the above effects are proven indirect socio-economic effects of increasing the sports activity of the population in the Russian regions.

Based on the use of the identified and quantitatively assessed channels of the influence of the sports activity of the population in the regions of Russia, the recoupment of costs for the preparation and implementation of major sports events includes the socio-economic effects obtained through these channels. Taking into account the influence of these channels when calculating the payback of sporting events makes it possible to form an extended payback model. This model is being tested on the example of the 2013 World Summer Universiade in Kazan.

The total budget of the 2013 Universiade was 128 billion rubles. Previous studies analyzed the basic direct and indirect economic effects of the preparation and holding of the 2013 Universiade for the economy of the Republic of Tatarstan [8].

The economic effect of infrastructure development in Kazan in this study is similarly calculated for the time period 2013-2018, taking into account the dynamics of the average salary of Kazan residents during this period (see Table 2).

Table 2. Average salary in Kazan in 2014-2018.

\begin{tabular}{|c|c|c|c|c|c|}
\hline & 2014 & 2015 & 2016 & 2017 & 2018 \\
\hline Salary, rubles & 32819 & 34741 & 37758 & 41021 & 44837 \\
\hline $\begin{array}{c}\text { Growth rate, annual, } \\
\%\end{array}$ & 111,0 & 105,9 & 108,7 & 108,6 & 109,3 \\
\hline
\end{tabular}

Data source: Reports of Territorial Department of the Federal state statistics service in the Republic of Tatarstan in Russia (Tatarstanstat).

The tourism potential of the Republic of Tatarstan as a result of the preparation and holding of the 2013 Universiade has significantly increased.

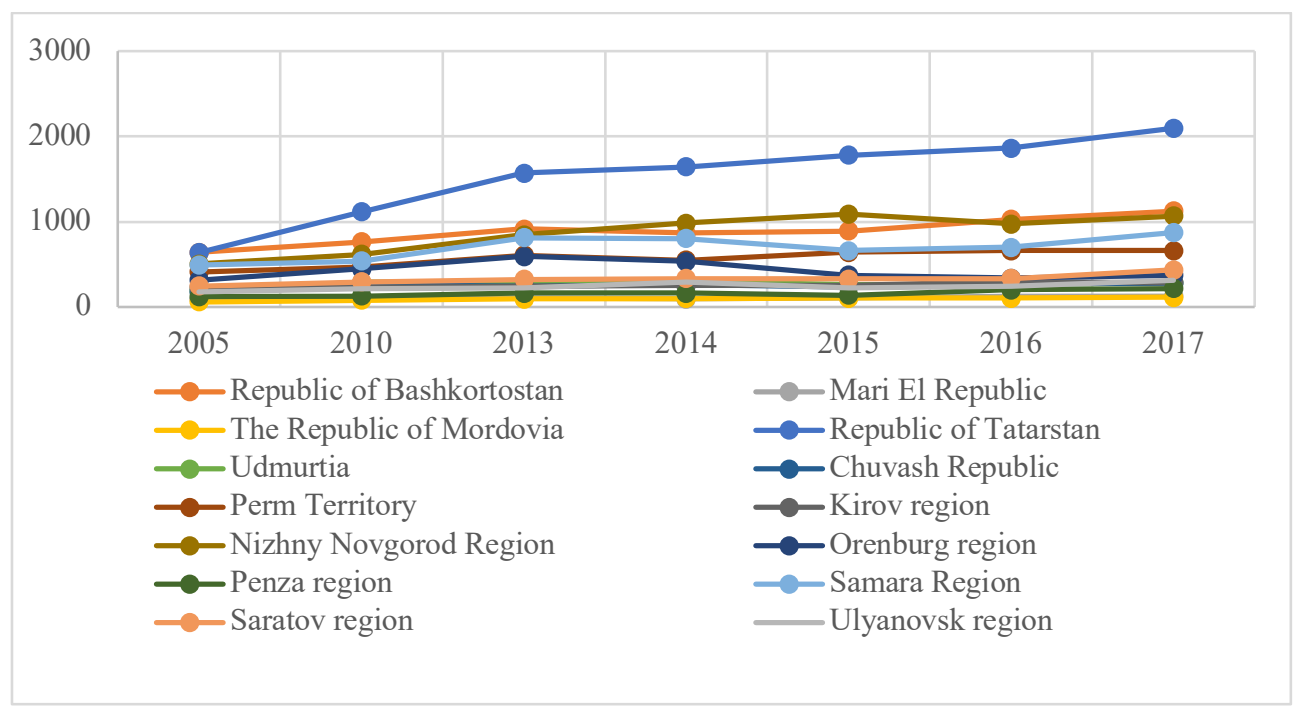

Fig. 2. Dynamics of the number of placements in collective accommodation facilities in the regions of the Volga Federal District, people. Built according to [10]. 
Figure 2 shows that during the preparation and holding the 2013 Universiade and subsequent years (starting from 2009), the tourist flow to the Republic of Tatarstan, one of the main indicators of which is the number of accommodations, began to grow steadily, with the growth rate, significantly exceeding the growth rates of the same indicator of the Volga Federal District.

In particular, over the period from 2009 to 2017, the number of placements in collective accommodation facilities in the Volga Federal District increased by $23 \%$, while the number of placements in the Republic of Tatarstan increased 2.8 times.

The growth of the tourist flow occurred as a result of the increased recognition and popularity of the city of Kazan and the Republic of Tatarstan as a result of the preparation and holding of the 2013 Universiade, the expansion of opportunities for holding major events at the facilities built in preparation for the Universiade (for example, the 2015 Aquatics Championship), the appearance of additional accommodation facilities (the Universiade Village, by 2013 new hotels were built and existing ones modernized), an increase in the comfort of the transport infrastructure, etc.

To calculate the economic effect from the development of inbound tourism in the Republic of Tatarstan, a scenario analysis was used. In particular, the baseline scenario is the growth of the tourist flow at the level of the average growth of this indicator in the Volga Federal District. As a result of comparing the actual tourist flow and the tourist flow calculated according to the baseline scenario, an additional tourist flow was obtained that arose as a result of the preparation and holding of the Universiade in accordance with Table 3.

Table 3. Calculation of the economic effect of the 2013 Universiade project in the field of tourism.

\begin{tabular}{|c|c|c|c|c|c|c|c|c|c|}
\hline Indicators & $\mathbf{2 0 0 9}$ & $\mathbf{2 0 1 0}$ & $\mathbf{2 0 1 1}$ & $\mathbf{2 0 1 2}$ & $\mathbf{2 0 1 3}$ & $\mathbf{2 0 1 4}$ & $\mathbf{2 0 1 5}$ & $\mathbf{2 0 1 6}$ & $\mathbf{2 0 1 7}$ \\
\hline $\begin{array}{c}\text { Number of placements in the } \\
\text { Republic of Tatarstan, actual, } \\
\text { thousand people }\end{array}$ & 989 & 1114 & 1239 & 1430 & 1570 & 1641 & 1782 & 1861 & 2096 \\
\hline $\begin{array}{c}\text { Estimated number of } \\
\text { placements in the Republic of } \\
\text { Tatarstan, with the growth } \\
\text { rate of the Volga Federal } \\
\text { District, thousand people }\end{array}$ & 760 & 780 & 800 & 820 & 841 & 863 & 884 & 907 & 931 \\
\hline $\begin{array}{c}\text { Excess of the number of } \\
\text { placements in the Republic of } \\
\text { Tatarstan due to higher } \\
\text { growth rates relative to the } \\
\text { Volga Federal District }\end{array}$ & 229 & 334 & 439 & 610 & 729 & 778 & 898 & 954 & 1165 \\
\hline $\begin{array}{c}\text { Economic effect from } \\
\text { additional number of } \\
\text { placements in the Republic of } \\
\text { Tatarstan, mln. rub. }\end{array}$ & 686 & 1001 & 1317 & 1831 & 2186 & 2335 & 2693 & 2862 & 3496 \\
\hline
\end{tabular}

Data source: Tatarstanstat.

The formation of additional value added as a result of the increased tourist flow is estimated on the basis of a number of minimum assumptions: the minimum average stay in the Republic of Tatarstan is two days with daily expenses for accommodation, meals, etc. 3 thousand rubles. The share of value added in the revenue from the above income is taken at the level of $50 \%$, which also corresponds to the minimum values for the hospitality industry.

In our previous research, the influence of sports activity on the morbidity rate of the population, expressed by the indicator "Number of days of temporary disability (per 100 people) per year" for a sample of 82 Russian regions for the period from 2008 to 2016, was strictly mathematically proved [11]. 
A similar dependence takes place for the Republic of Tatarstan. According to Figure 3, it follows that with an increase in sports activity (the proportion of regularly engaged in physical culture and sports) by one percent, the number of days of temporary disability (per 100 people) decreases by 18.75 days.

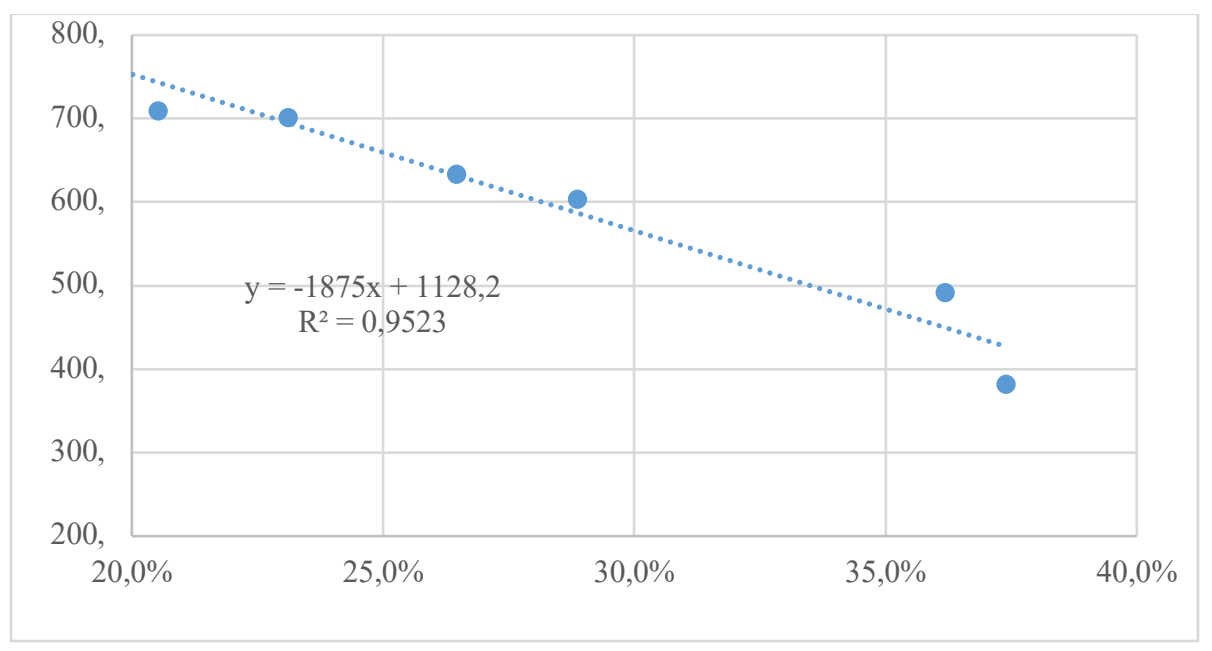

Fig. 3. Decrease in days of temporary disability.

Note - Decrease in days of temporary disability (per 100 people) per year as a result of an increase in the sports activity of the population in the Republic of Tatarstan (according to previously constructed models, the explanatory variable is taken with a lag of 2 years).

To determine the role of the 2013 Universiade, one should refer to the dynamics of this indicator in the period before and after 2013 in accordance with Figure 4.

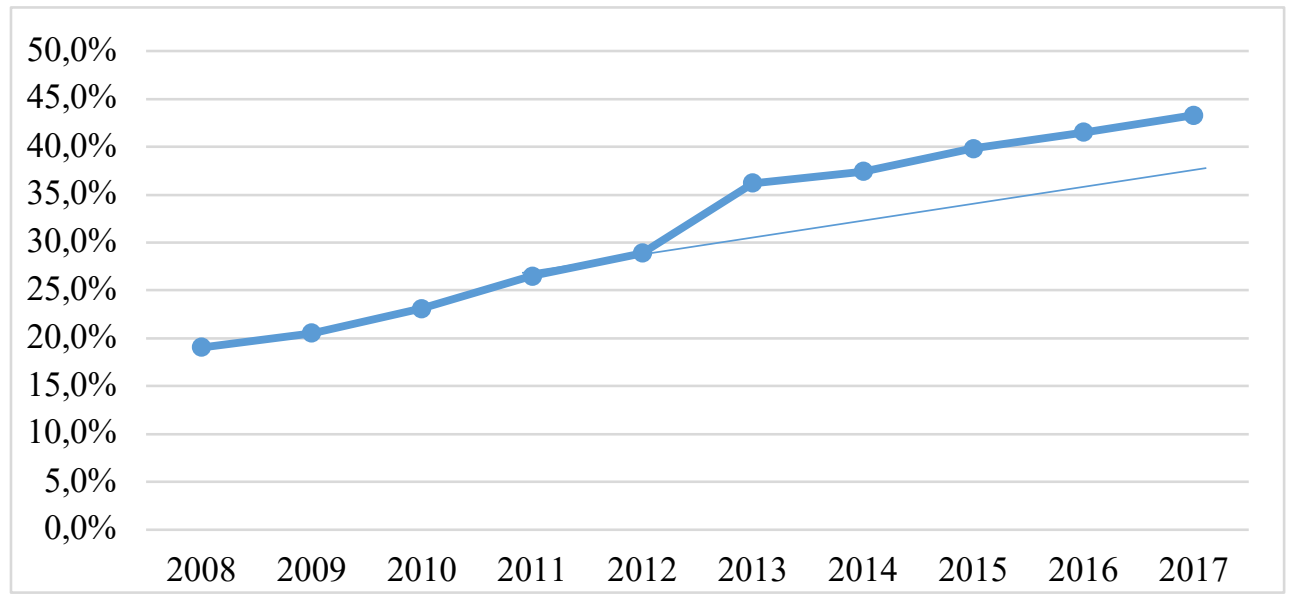

Fig. 4. Dynamics of sports activity of the population in the Republic of Tatarstan [12].

Figure 4 clearly shows that the 2013 Universiade led to a one-time abrupt increase in the sports activity of the population in 2013 in the Republic of Tatarstan by an average of 5\%.

Consequently, the constant excess of sports activity by $5 \%$ per year of the Universiade 2013 led to an additional decrease in the incidence of the population, starting from 2015, expressed in a decrease in the number of days of disability (hereinafter referred to as ND) by 
93 days per year for every 100 residents of the Republic of Tatarstan (hereinafter, this indicator of decline is designated as NDA).

Reducing the number of days of disability for the population has two significant economic effects. Firstly, the load on the regional health care system is reduced, as a result, the current budget expenditures for the provision of medical services are reduced. Secondly, the labor productivity of the economically active population rises.

The value of the ratio of NDA to the total value of ND is used to assess the reduction in budget expenditures in the health sector. It is assumed that the number of days of disability characterizes equally all types of diseases and medical measures.

In this case, the effect of a decrease in the ND indicator as a result of an increase in sports activity will proportionally reduce the current budget expenditures on health care (see Table 4).

Table 4. Assessment of the reduction in health care costs in the Republic of Tatarstan as an indirect effect of the implementation of the 2013 Universiade project in Kazan.

\begin{tabular}{|c|c|c|c|c|}
\hline Indicator & 2015 & 2016 & 2017 & 2018 \\
\hline $\begin{array}{c}\text { Expenditures of the consolidated budget of the } \\
\text { Republic of Tatarstan on health care, million rubles }\end{array}$ & 49089 & 50607 & 52172 & 53786 \\
\hline ND & 490,8 & 381,1 & 300,0 & 220,0 \\
\hline NDA & 93 & 93 & 80 & 60 \\
\hline ND before reduction, ND+NDA & 584 & 474 & 380 & 280 \\
\hline Percentage reduction in ND & $16 \%$ & $20 \%$ & $21 \%$ & $21 \%$ \\
\hline $\begin{array}{c}\text { The effect of reducing the incidence of the population } \\
\text { in the form of savings in health care costs, million } \\
\text { rubles }\end{array}$ & 7820 & 9927 & 10984 & 11526 \\
\hline
\end{tabular}

Data source: Tatarstanstat.

A decrease in the number of days of disability is observed as a consequence of an increase in sports activity with a time lag of two years, the economic effect based on a decrease in health care costs (as well as as a result of an increase in labor productivity, see below) has been observed since 2015, that is, after two years after a spasmodic increase in sports activity in the Republic of Tatarstan as a result of the 2013 Universiade in Kazan in accordance with Table 4.

In addition, Table 4 provides for a decrease in the NDA indicator in 2017, 2018 as a result of taking into account the decrease in the Universiade effect in these years according to Figure 4.

A decrease in the number of days of incapacity for work leads to an increase in the working time of the economically active population, as a result, its labor productivity increases. To assess the economic effect of such an increase, it should be taken into account that a decrease in days of incapacity for work increases the number of days of active work. Consequently, this fact should be accepted as a conditional increase in labor power, all other things being equal. The economic effect is estimated on the basis of the total number of additional working months multiplied by the average monthly salary in the region by year, taking into account social contributions. Similarly to previous estimates of the economic effect of saving health care costs, the economic effect based on an increase in labor productivity has been taking place since 2015 , that is, also two years after the abrupt growth of sports activity in the Republic of Tatarstan as a result of the 2013 Universiade in Kazan (see Table 5). 
Table 5. Calculation of the economic effect from the growth of labor productivity as a result of a decrease in the indicator "Number of days of incapacity for work per 100 inhabitants" in the Republic of Tatarstan as a result of the implementation of the 2013 Universiade project in Kazan.

\begin{tabular}{|c|c|c|c|c|}
\hline Indicators $\backslash$ years & 2015 & 2016 & 2017 & 2018 \\
\hline Population, thousand people & 3861,9 & 3877 & 3889,8 & 3885 \\
\hline Average monthly salary, rubles & 29147 & 30224 & 32324 & 35000 \\
\hline Economic effect, million rubles & 6480 & 6746 & 7239 & 7828 \\
\hline
\end{tabular}

So, on the basis of the previously constructed econometric models that substantiate the channels of influence of sports activity on the socio-economic situation of the regions of Russia, the main direct and indirect economic effects of the project for the preparation and holding of the 2013 Universiade in Kazan were revealed.

The recoupment of the 2013 Universiade project is estimated using the traditional discounted cash flow method, the estimated discount rate is adopted at the level of $10 \%$ (the refinancing rate of the Central Bank of the Russian Federation plus a premium of about $2 \%$ at the time of the project implementation).

As a result of the aggregate estimate of the above identified and substantiated positive effects, an expanded model for assessing the payback of large sporting events has been developed, including investments in the infrastructure capital of the region and a number of intangible assets (see Table 6). It has been tested using data from the 2013 Universiade project.

Table 6. Calculation of the payback of the 2013 Universiade project in Kazan due to the indirect effects of the growth of sports activity in the Republic of Tatarstan, million rubles. Source: own calculations.

\begin{tabular}{|c|c|c|c|c|c|c|c|c|c|}
\hline Project years & 2013 & 2014 & 2015 & 2016 & 2017 & 2018 & 2019 & 2020 \\
\hline Effects & \multicolumn{6}{|c|}{ Assessment of the economic effects of the Universiade by years, mln rubles } \\
\hline $\begin{array}{c}\text { Infrastructure } \\
\text { effect }\end{array}$ & 2199 & 2419 & 2561 & 2784 & 3024 & 3305 & 3570 & 3855 \\
\hline $\begin{array}{c}\text { Budget } \\
\text { expenditures } \\
\text { saving (for } \\
\text { health care) }\end{array}$ & 0 & 0 & 7820 & 9927 & 10984 & 11526 & 11526 & 11526 \\
\hline $\begin{array}{c}\text { Productivity } \\
\text { growth }\end{array}$ & 0 & 0 & 6480 & 6746 & 7239 & 7828 & 8455 & 9131 \\
\hline $\begin{array}{c}\text { Social capital } \\
\text { contribution }\end{array}$ & 17556 & 17556 & 17556 & 17556 & 17556 & 17556 & 17556 & 17556 \\
\hline $\begin{array}{c}\text { Add. tourism } \\
\text { revenues }\end{array}$ & 2186 & 2335 & 2693 & 2862 & 3496 & 4272 & 5219 & 6377 \\
\hline $\begin{array}{c}\text { Total project } \\
\text { revenues }\end{array}$ & $\mathbf{2 1 9 4 2}$ & $\mathbf{2 2 3 1 1}$ & $\mathbf{3 7 1 1 1}$ & $\mathbf{3 9 8 7 4}$ & $\mathbf{4 2 2 9 9}$ & $\mathbf{4 4 4 8 7}$ & $\mathbf{4 6 3 2 5}$ & $\mathbf{4 8 4 4 5}$ \\
\hline $\begin{array}{c}\text { Discounting } \\
\text { rate, 10\% per } \\
\text { year }\end{array}$ & 0,909 & 0,826 & 0,751 & 0,683 & 0,621 & 0,564 & 0,513 & 0,467 \\
\hline $\begin{array}{c}\text { Discounted } \\
\text { cash flow }\end{array}$ & 19947 & 18439 & 27882 & 27235 & 26264 & 25112 & 23772 & 22600 \\
\hline $\begin{array}{c}\text { Accumulated } \\
\text { positive. cash } \\
\text { flow }\end{array}$ & 19947 & 38386 & 66267 & 93502 & 119766 & 144878 & 168650 & 191250 \\
\hline $\begin{array}{c}\text { Accumulated } \\
\text { net cash flow }\end{array}$ & -109053 & -90614 & -62733 & -35498 & -9234 & 15878 & 39650 & 62250 \\
\hline
\end{tabular}




\section{The discussion of the results}

Investment and operating costs for the preparation and holding of the 2013 Universiade in Kazan amounted to 129 billion rubles. Taking into account the dynamics of investments within the framework of the 2013 Universiade project, that is, the distributed nature of investment costs during the preparation for the Universiade, the estimated year of investment should be considered 2011 as the weighted average of the periods of all investment costs in the period of preparation for the Universiade.

Therefore, according to the data in Table 6, the project investments were paid off in 2018 (the net accumulated discounted cash flow becomes positive in this year).

The payback period of the project (discounted, taking into account the time value of money) based on indirect effects is 7 years.

\section{Conclusion}

The results obtained in this study, combined with the results obtained in other works discussed above, made it possible to substantiate a number of channels of the influence of the sports activity of the Russian population on the economic development of Russian regions. They, in turn, will serve as the basis for predicting the socio-economic effects of the growth of sports activity. An assessment of these effects is necessary to substantiate the economic efficiency and payback of projects for investment and financing activities in the field of physical culture and sports. Within the framework of this study, the constructed models were tested in the framework of their use as auxiliary tools for assessing the payback of the project for the preparation and holding of the 2013 Universiade in Kazan.

An expanded model for assessing the payback of large sporting events has been formed and tested, including investments in the infrastructure capital of the region and a number of intangible assets, using the example of the Republic of Tatarstan. The payback period of the Universiade-2013 project (discounted, taking into account the time value of money) based on indirect effects was 7 years.

\section{Acknowledgment}

This work was carried out with the financial support of the Kazan Innovative University named after V.G. Timiryasov (IEML).

\section{References}

1. K. Sanderson, F. Harris, S. Russell \& S. Chase, The Economic Benefits of Sport A Review, Hong Kong: Business and Economic Research Limited (2000)

2. H. J. Gibson, Sport Tourism: a Critical Analysis for Research, Sport management Review, 1, 45-76 (1998)

3. H. J. Gibson, Sport Tourism at a Crossroad? Considerations for the Future, in Gammon S., Kurtzman J. (acura di), Sport Tourism: principles and practice. Eastbourne: Leisure Studies Association, 76, 111-128 (2002)

4. C. Pigeassou, Sport Tourism, a Growing Sector: Issues and Perspectives in France, Sport tourism: principles and practice, 129-140 (2002) 
5. M.R. Miftakhov, M.M. Bariev, T.V. Kramin, People's Sport Activity as a Factor of Economic Growth (Case Study of Kazan), Theory and Practice of Physical Culture, 5, 49-52 (2017)

6. NACE Rev. 2 - Statistical classification of economic activites in the European Community. Eurostat Methodologies and Working papers, European Communities, (2008). URL: https://ec.europa.eu/eurostat/documents/3859598/5902521/KS-RA-07015-EN.PDF

7. Study on the Contribution of Sport to Economic Growth and Employment in the EU. Study commissioned by the European Commission, Directorate-General Education and Culture. Final Report (2012)

8. M.R. Miftakhov, T.V. Kramin, M.M. Bariev, Socio-Economic Aspects of the Effectiveness of State Policy to Increase the Sports Activity of the Population, Physical culture and health, 4 (64), 37-42 (2017)

9. A.R. Klimanova, Assessment of the Impact of Social Capital on Entrepreneurial Activity in Russian Regions, Actual problems of economics and law, 13, 1 (49), 966-980 (2019)

10. Federal Agency of State Statistics, Annual report "Regions of Russia. Social-economic indicators". URL: https://www.gks.ru/free_doc/doc_2018/region/reg-pok18.pdf

11. T.V. Kramin, M.R. Miftahov, W. Andreff, Sport Activity of Russian Population as a Factor of Socio-Economic Development, European Proceedings of Social and Behavioural Sciences (EpSBS), II International Scientific Conference GCPMED 2019 "Global Challenges and Prospects of the Modern Economic Development", 86-92 (2019)

12. Indicators of the development of physical culture and sports in the context of the constituent entities of the Russian Federation. Annual reports of the Ministry of Sports of the Russian Federation. URL: https://www.minsport.gov.ru/sport/physicalculture/statisticheskaya-inf 